\title{
High strain dynamic testing of driven piles during the construction of the bridge across the Kerch Strait
}

\author{
Ilia Glushkov, ${ }^{1, *}$ \\ ${ }^{1}$ Perm National Research Polytechnic University, Perm, Perm region, 614990, Russia
}

\begin{abstract}
In accordance with the Russian Federal Target Program of Social and Economic Development of the Crimea and Sevastopol, a bridge across the Kerch Strait is being built now. Of course, such complex structures are significant for Russia. Solving technical issues at different stages of engineering investigations, design, construction and operation of such objects it is required to attract specialists from scientific, educational, design, construction organizations, and manufacturers of building materials, structures and equipment from different countries. Before the implementation of this project, more than 70 different variations of the construction of the transport crossing were considered. These are combinations of bridges (cable, arched, girder, combined, etc.), tunnels and embankments in four sections of the Kerch Strait. As a result of the multifactor analysis, the optimal variation of the transition through the Tuzla point of two parallel bridges of about $19 \mathrm{~km}$ in length, with beam spans of 55-64 m, arches with a width of $227 \mathrm{~m}$ and a height of $45 \mathrm{~m}$ in the navigable channel was adopted. The bridge clearance for passage of ships is $185 \times 35 \mathrm{~m}$. To design a unique and complex bridge under existing regulations, special technical conditions were developed. When piles were driven, there were difficulties and issues that required prompt solutions. Employees of the Department of Highways and Bridges of the Perm National Research Polytechnic University were involved in testing piles and hammers. The design of foundations and the technology of driving piles were changed as the test results were obtained.
\end{abstract}

\section{Introduction}

The transport passage through the Kerch Strait is located in the Krasnodar Region of the Russian Federation (the Taman Peninsula) and the Republic of the Crimea, as shown in Fig. 1. The construction of the passage passes through Tuzla Island, the length of the passage through the water area of the Strait is about $19 \mathrm{~km}$. The beginning of the passage is on the Taman Peninsula in the area of the Tuzla spit. Then the passage through the Tuzla closure channel goes to Tuzla Island. On the island the passage passes mainly along the south-west coast for all $6.5 \mathrm{~km}$. Then, crossing the Kerch-Yenikal channel in the direction of the city of Kerch the passage leads to the Crimean coast [1-2].

\footnotetext{
*Corresponding author: givperm@mail.ru
} 
For the construction this region is characterized by a continental climate of temperate latitudes with predominance of cyclonic type of circulation of continental and marine air masses, with very warm summers and moderately mild cloudy winters. The duration of the unfavorable period is 4.5-5 months, as a rule, from November 15 to April 15. Navigation in the Kerch Strait is carried out all the year round and can be slightly hampered during the ice formation.

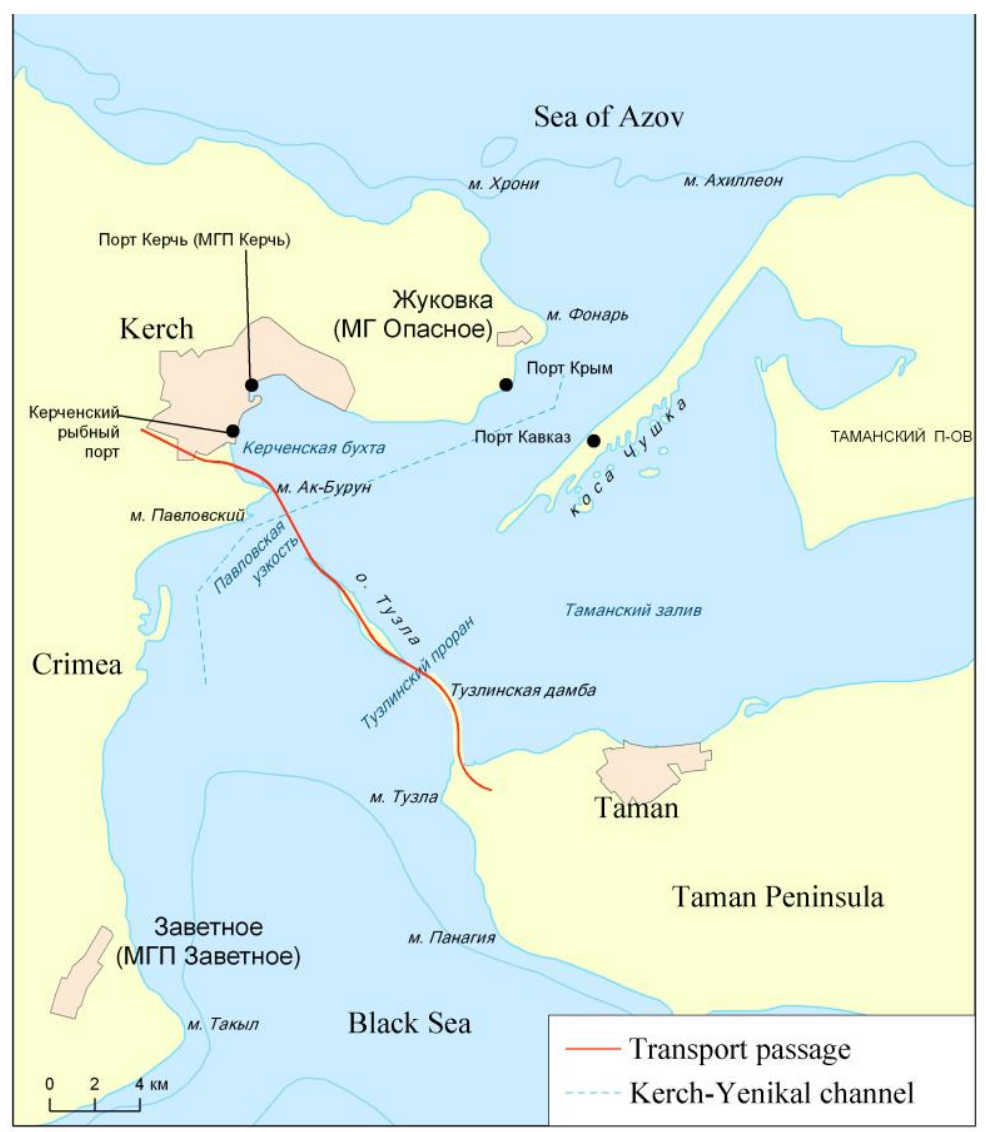

Fig. 1. Scheme of the location of the transport crossing through the Kerch Strait.

The peculiarity of the ice conditions of the Kerch Strait is their instability - during the freezing period, the appearance and disappearance of the ice under the influence of the wind and currents is possible. As a result of an ice drift, its bulk is possible on the island of Tuzla and on separate parts of the Tuzla Dam. Drifting ice can pose a real threat to the structures of the bridge.

The construction site is located in difficult geological conditions. There are dangerous geodynamic processes here: landslides and gully erosion on the Kerch coast, deflationaryaccumulative aeolian processes on the Tuzla spit and island, mud volcanism on the Taman Peninsula, everywhere accumulative abrasion activity of the Azov Sea is viewed.

The upper stratum of the geological section is composed of soils with a very low bearing capacity: swelling, organic, fluid, dynamically unstable.

The transport passage includes the following structures: bridge for a four-lane road, bridge for a two-way railway, buildings and facilities for operating bases, embankments.

The shipping spans over $200 \mathrm{~m}$ in length are covered with steel arches. On the other sections of the transport passage split and continuous types of the beam, spans are used. 
The basis for pile foundations, as a rule, is the deposition of the Miocene. In addition to standard types of concrete piles, steel tubular piles with an open end are used.

\section{Technical parameters of the transport passage}

- 2 parallel bridges $19 \mathrm{~km}$ long for a four-lane highway and a double-track railway.

- Beam spans with a length of 55-64 m.

- In the navigable waterway, the arch is $227 \mathrm{~m}$ wide, $45 \mathrm{~m}$ high. The bridge clearance for passage of ships is $185 \times 35 \mathrm{~m}$.

- Foundations - steel tubular piles with a cap.

- According to the conditions of interaction with the soils, all piles are friction.

\section{Geological conditions of the construction site}

In the geological structure of the territory of the construction of the transport passage take part (top-down) [1]:

- Late-Holocene marine sediments of the New Black Sea age (geological index $\mathrm{mQIVnch}$ ), represented by watery sands of silty, small, medium size and large, clayey soils of fluid consistency with an admixture of organic matter.

- Early Middle Holocene marine sediments of the Old Black Sea age (geological index mQIVdch), represented by clay soils from a fluid to a hard consistency with an admixture of organic matter.

- Upper Pleistocene alluvial deposits (geological index aQIII), represented by dense and medium-density water-saturated silty, fine and medium-sized sands, with shells.

- Neogene deposits of the Sarmatian stage (geological index N1s), represented by sands of medium size and medium density, hard clays, with inclusions of the shell, with an admixture of organic matter.

The geological structure has been studied to a depth of $100 \mathrm{~m}$.

The total thickness of quaternary deposits reaches $50 \mathrm{~m}$.

The seismicity of the construction area on the MSK-64 scale is 8-9 points.

\section{General parameters of foundations with driven steel tubular piles}

The length of steel tubular piles varies within $70-90 \mathrm{~m}$, part of the piles in the foundations are made with an inclination of $1 \mathrm{~V}: 5 \mathrm{H}$, the wall thickness is $20 \mathrm{~mm}$. As shown in Fig. 2, the piles are made of $1420 \mathrm{~mm}$ steel pipes, steel corresponds to ASTM A516. The upper outside surface of the pipes has an anti-corrosion coating. The inner upper part of the pipes after the driving is filled with hydrotechnical concrete C30/37.

The bearing capacity of tubular piles for the project on different sites is 9-16 MN.

\section{Driving of the steel tubular piles}

Based on the analysis of geological conditions, calculations were performed and the parameters of the equipment for pile driving were selected.

At the beginning of the pile driving, the following problems appeared: reaching the calculated values of a pile set with a smaller depth of penetration, frequent breakdowns of the hammers and, as a consequence, poor hammer performance. 


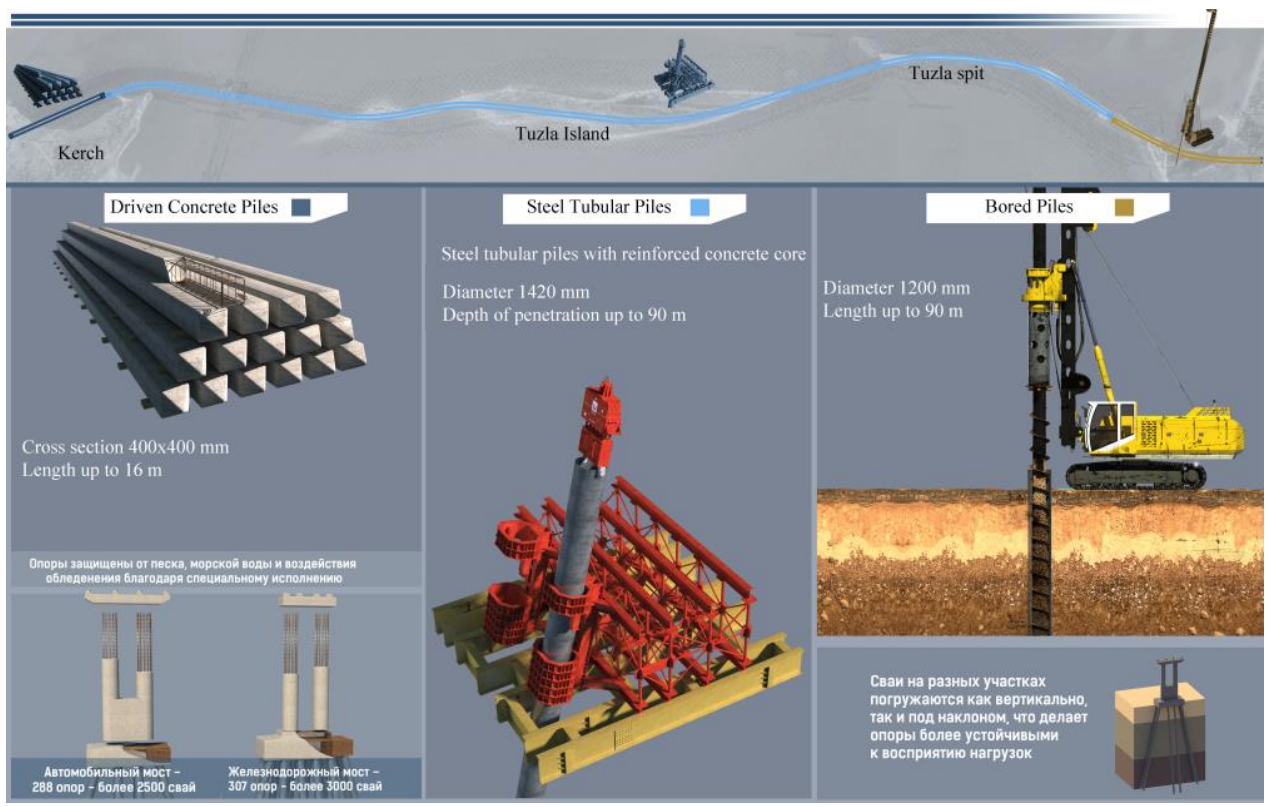

Fig. 2. Types of pile foundations.

\section{Testing of piles and modeling}

To solve problems and determine the bearing capacity of piles, the following tasks were assigned to our team [3]:

- Measure the transferred energy of hammers, shown in Table 1 and Fig. 3.

- Determine the possibility of pile driving to the intended depth and the bearing capacity of piles by GRLWEAP.

- Determine the bearing capacity of piles as a result of field tests using CAPWAP.

- Compare the bearing capacity of piles obtained by calculation and according to the test results, with the accepted design in.

Table 1. Equipment used for driving steel tubular piles.

\begin{tabular}{|c|c|c|c|}
\hline Hammer & Type of hammer & RAM weight, $\mathrm{kN}$ & Energy, $\mathrm{kJ}$ \\
\hline JUNTTAN HHK 25S & Hydraulic & 25 & 368 \\
\hline JUNTTAN HHK 28S & Hydraulic & 28 & 412 \\
\hline IMPACT 35D 515 & Hydraulic & 35 & 515 \\
\hline IHC S-500 & Hydraulic & 25 & 500 \\
\hline BRUS SGH2815 & Hydraulic & 28 & 412 \\
\hline MGE-720 & Free drop & 18 & 720 \\
\hline
\end{tabular}

When measuring the transferred energy, a low efficiency of hydraulic hammers was established, which was 40-60\%, as shown in Fig. 4. When the hammer struck a pile, large energy losses were observed. To solve this problem, new constructions of conductors for pile driving were quickly developed, connection of a hammer and pile were modernized, and changes were made to the hydraulic system and the hammer control programs. After eliminating the problems, the efficiency of the hammers increased to $80-90 \%$.

According to the measurements, a real model of the "hammer-pile-soil" system was modeled in the GRLWEAP program and calculations, as shown in Fig. 5, were made of the possibility of driving steel tubular piles at the planned depth. 

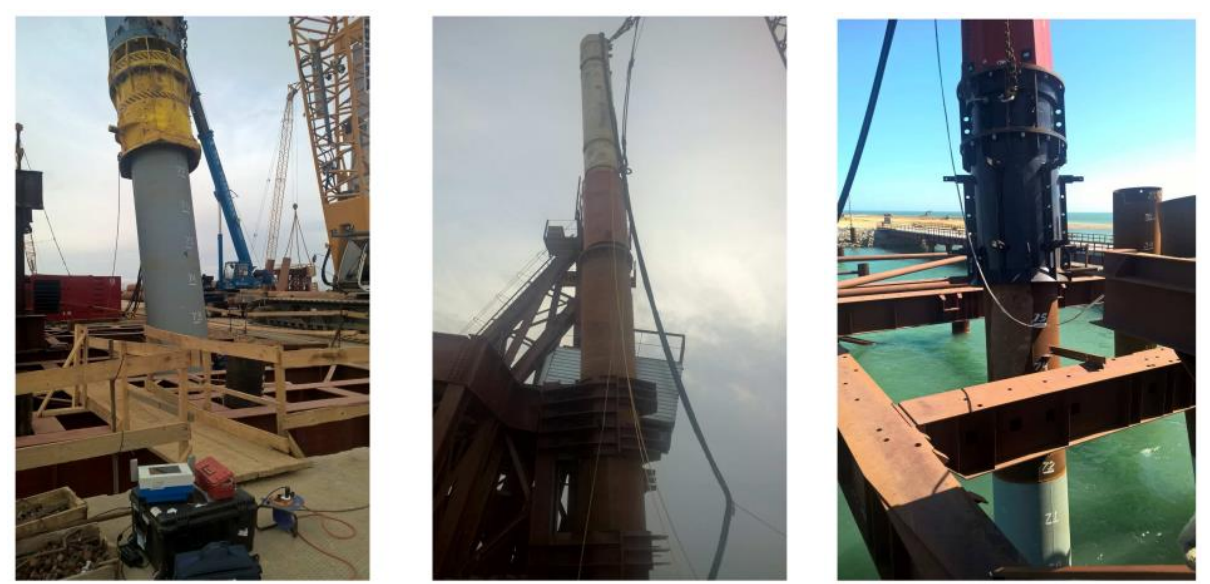

Fig. 3. Carrying out a PDA test.

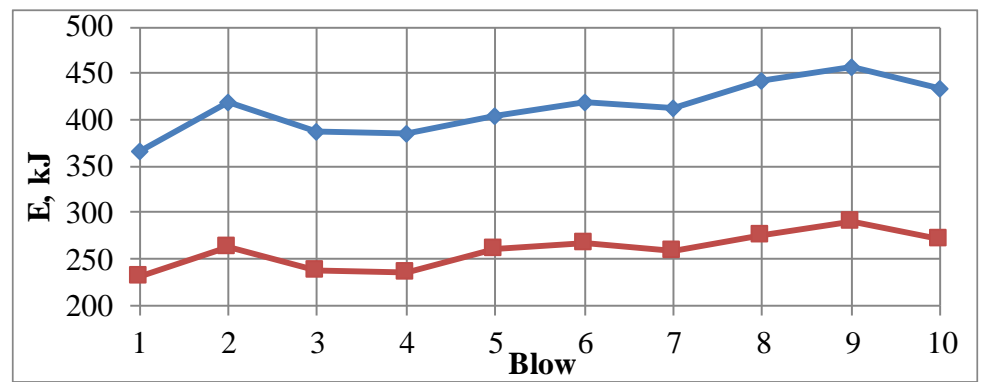

JUNTTAN HHK 28S
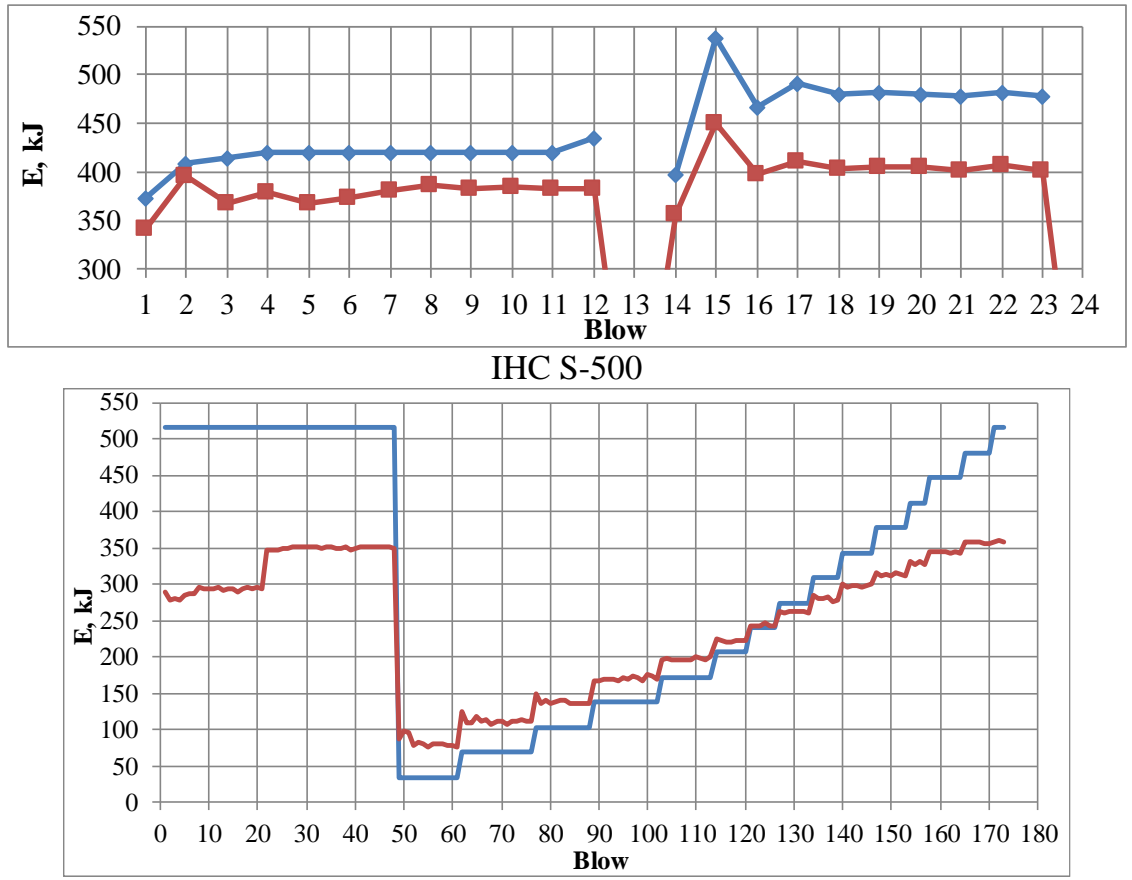

IMPACT 35D 515

Fig. 4. Results of measuring of the transferred energy of some hammers. 


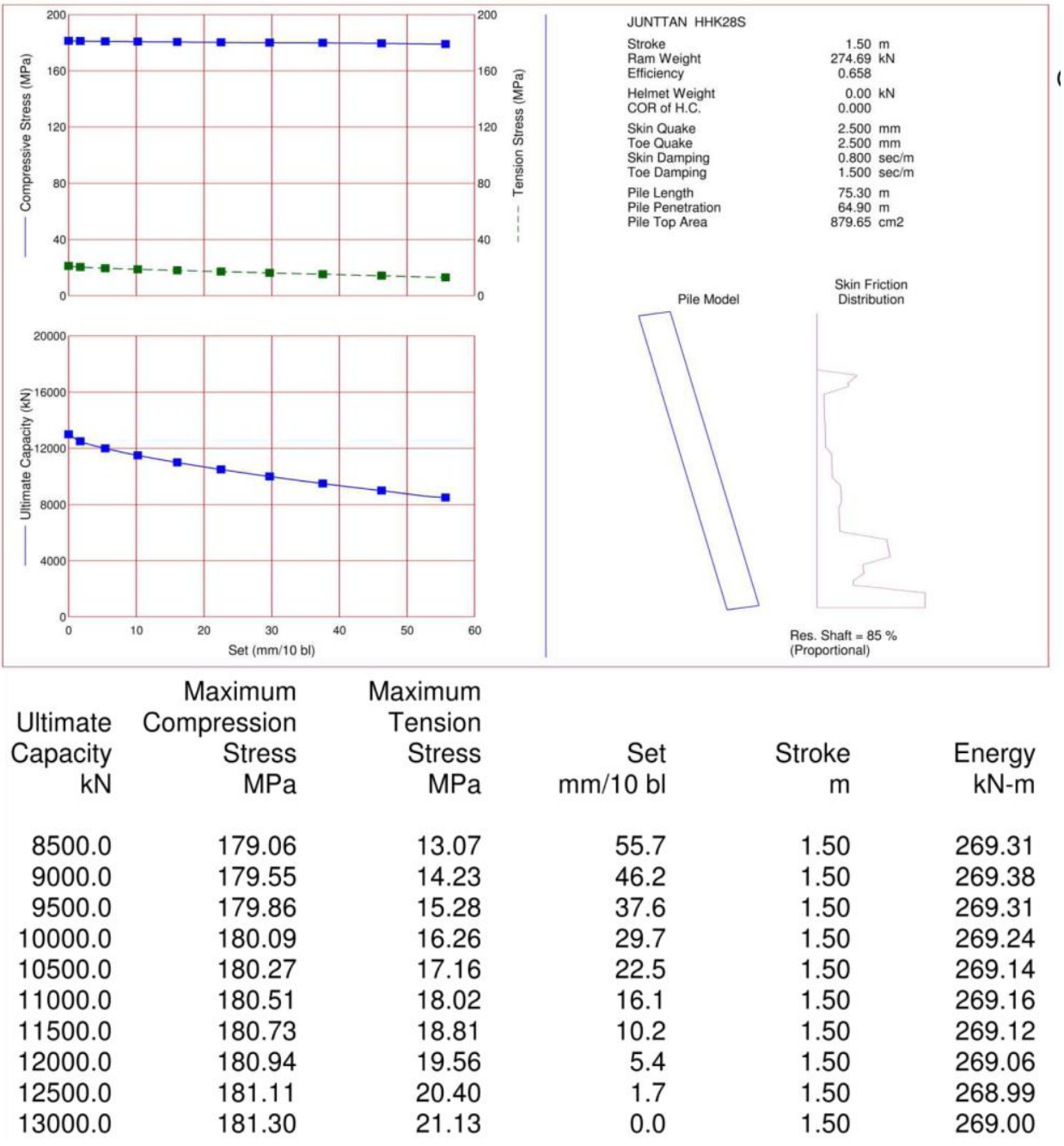

Fig. 5. The result of modeling in GRLWEAP.

To compare the results of measurements and simulation of the "hammer-pile-soil" system and determine the bearing capacity, the PDA measurements in the CAPWAP program were analyzed, as shown in Fig. 6 . The results of the analysis fully confirmed the calculations in GRLWEAP.

At the time of the tests, there was no possibility of comparing and correcting the results of either the dynamic tests PDA and CAPWAP, or modeling the "hammer-pile-soil" system in GRLWEAP (both solutions based on the stress wave theory), with static tests of the piles. A control static calculation of the "soil-pile" system was performed in the geotechnical computation complex PLAXIS, which is a package of applied computational programs for finite element geotechnical analysis (shown in Fig. 7). 

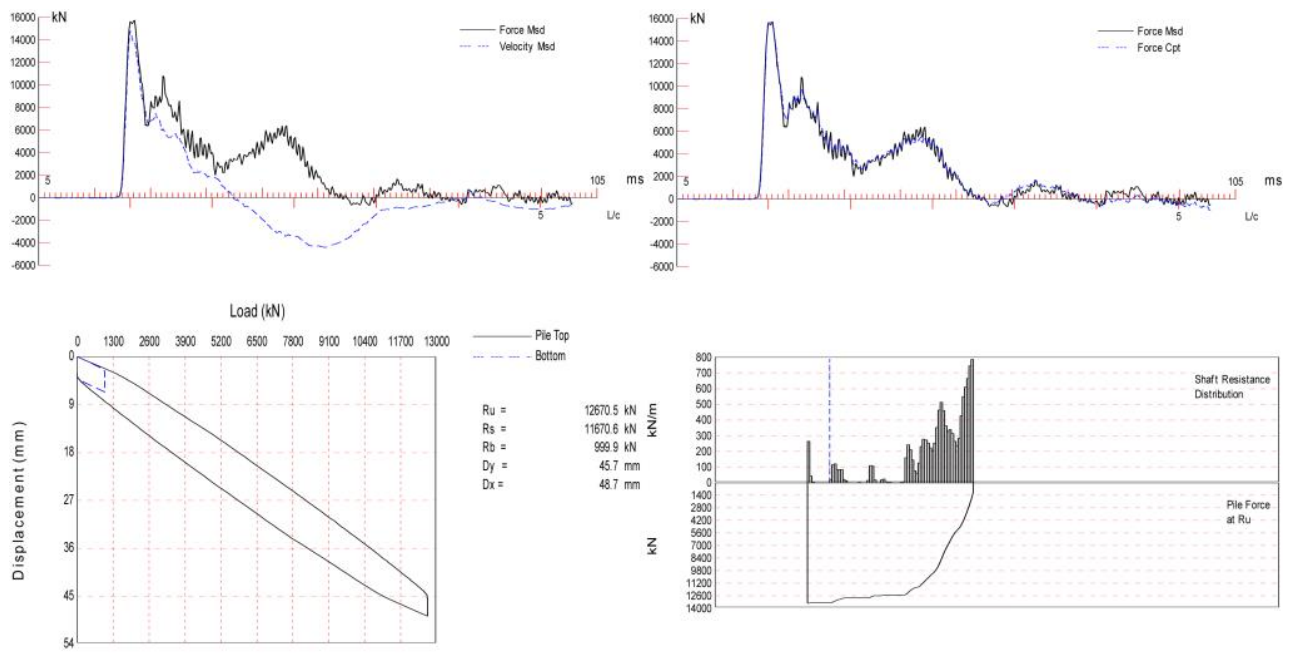

Fig. 6. Analysis result in CAPWAP.

Comparison of the results of PDA tests, modeling in GRLWEAP, CAPWAP and PLAXIS showed a high degree of correspondence of the main indicators (set, temporary set, bearing capacity, distribution of friction, energy, the graph of "load-settlement", etc.), as observed in Figures 8 and 9 and Table 2.

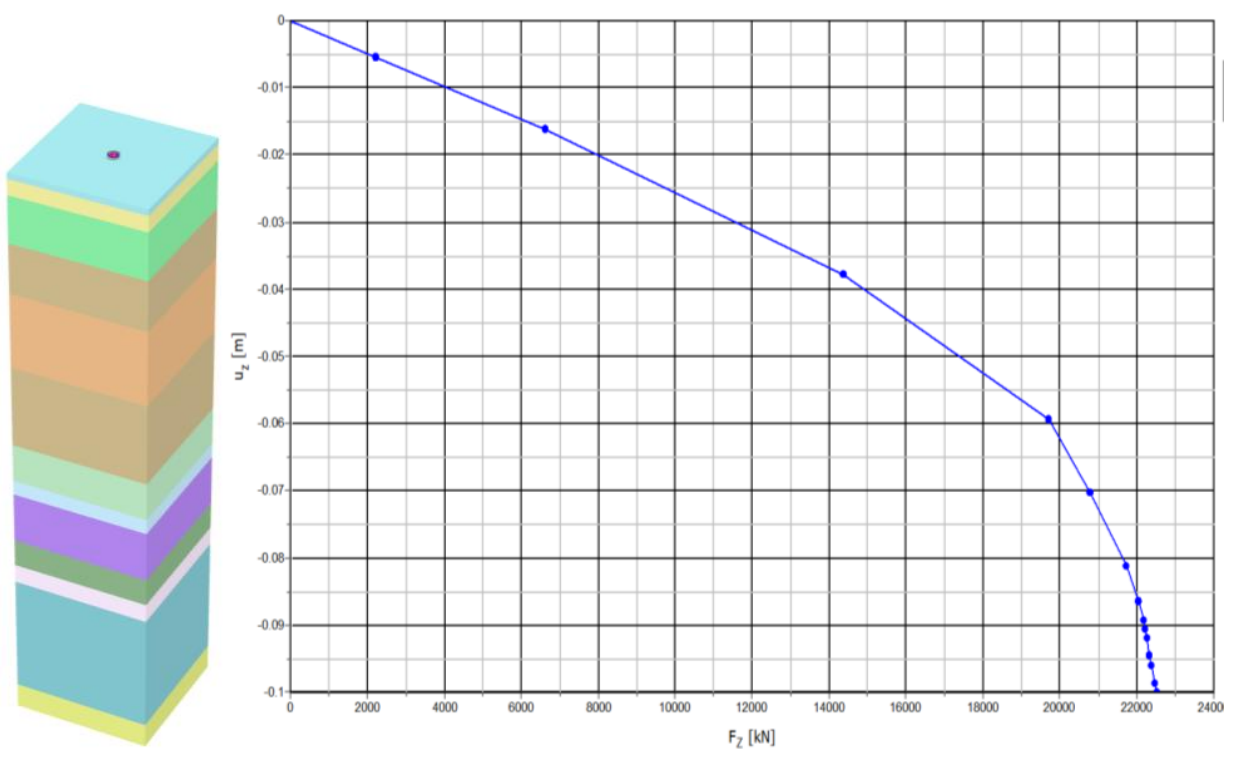

Fig. 7. Static pile loading results in PLAXIS. 


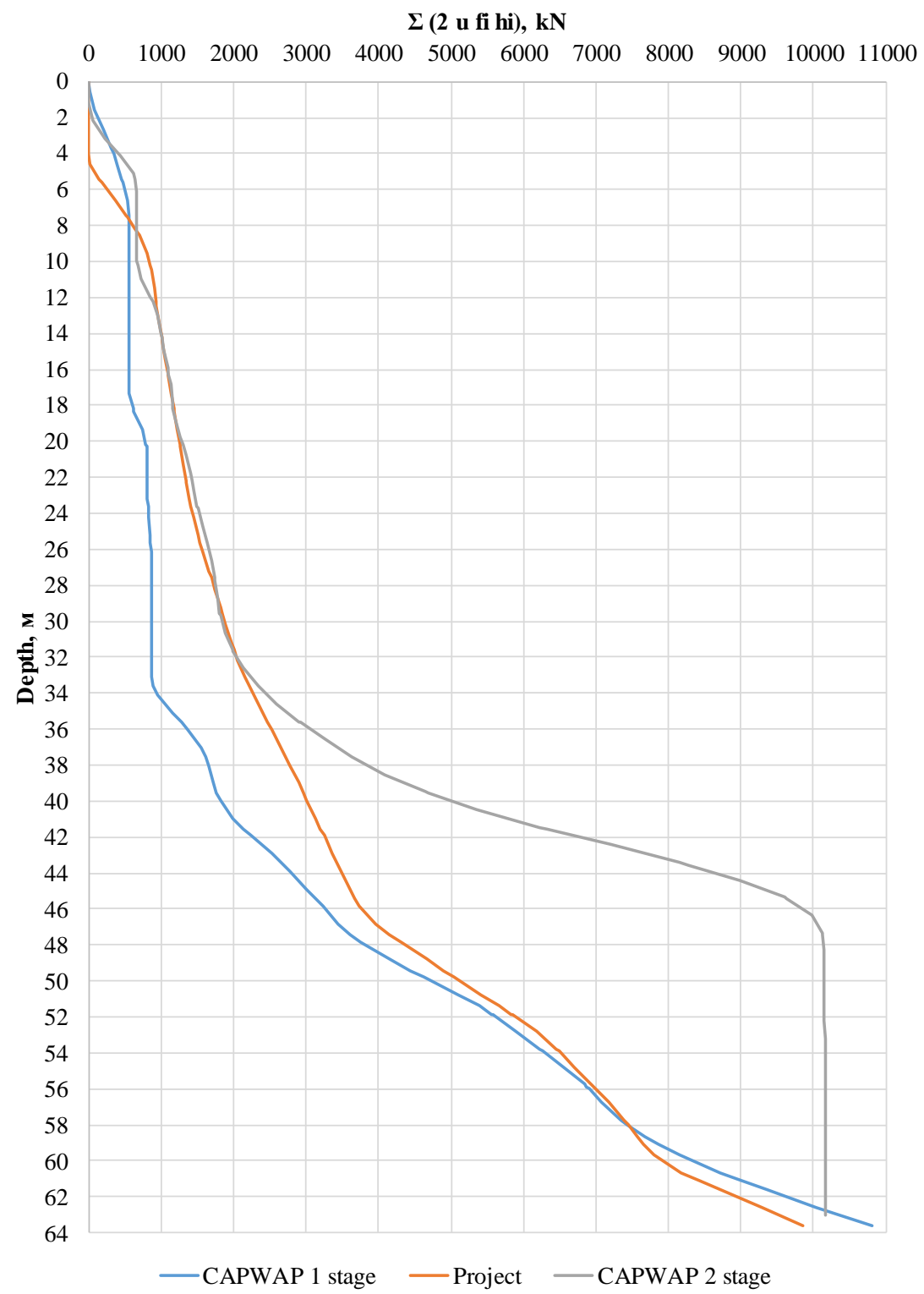

Fig. 8. Results of the comparison of soil resistance distribution according to CAPWAP with the project: CAPWAP 1 stage - PDA test when pile driving, Project corresponds to calculations according to building codes, CAPWAP 2 stage - PDA test 6 days after pile driving.

Table 2. Comparison of test results and modeling with the project.

\begin{tabular}{|c|c|c|c|c|c|c|c|}
\hline & \multicolumn{2}{|c|}{ CAPWAP } & \multicolumn{2}{c|}{ Measured } & \multicolumn{2}{c|}{ GRLWEAP } & \multirow{2}{*}{ Project } \\
\cline { 2 - 7 } & 1 stage & 2 stage & 1 stage & 2 stage & 1 stage & 2 stage & \\
\hline $\mathrm{R}_{\mathrm{U}}, \mathrm{kN}$ & 12671 & 13344 & - & - & 9925 & 11750 & 11428 \\
\hline $\mathrm{Rs}_{\mathrm{n}} \mathrm{kN}$ & 11671 & 10522 & - & - & - & - & 9669 \\
\hline $\mathrm{R}_{\mathrm{B}}, \mathrm{kN}$ & 1000 & 2821 & - & - & - & - & 1759 \\
\hline Temporary set, mm & 25.85 & 25.61 & 25.31 & 24.60 & - & - & - \\
\hline Set, mm & 3.09 & 0.66 & 3.09 & 0.66 & 3.09 & 0.66 & - \\
\hline
\end{tabular}

At the last stages of the construction, field static load tests of the pile were carried out. 
The test results show a high correlation with static calculations in PLAXIS.

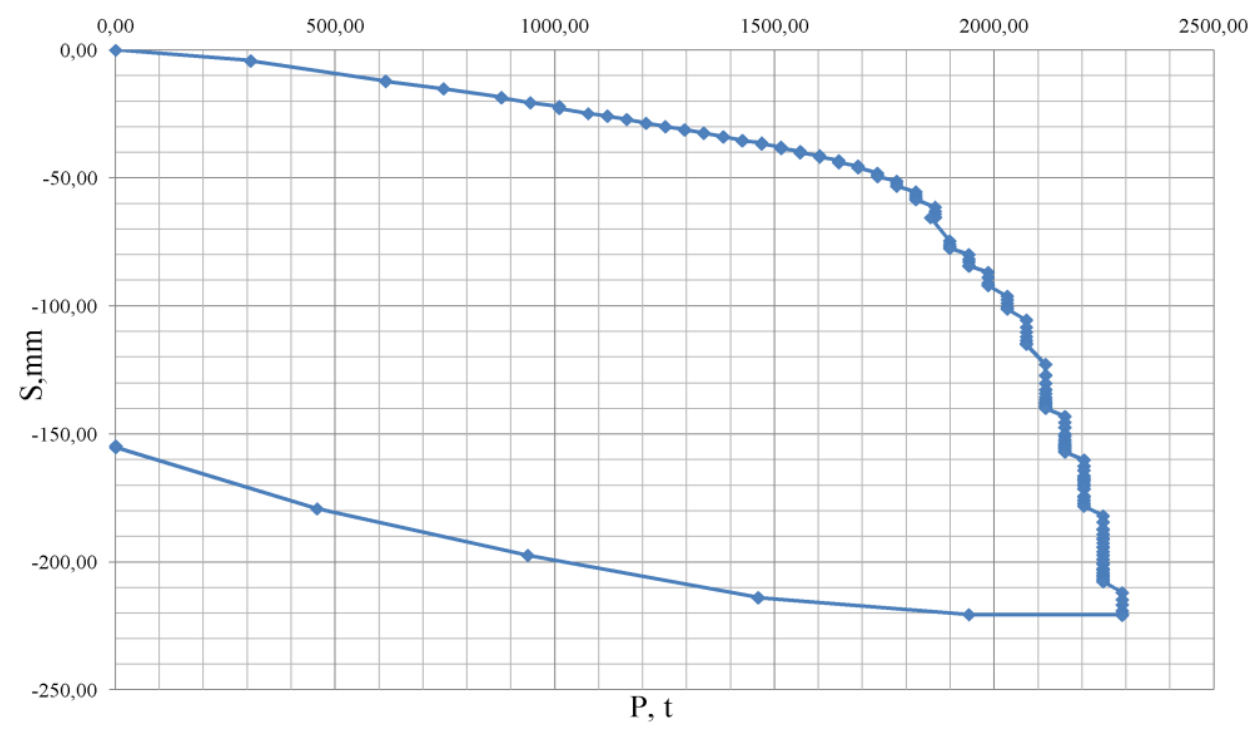

Fig. 9. Results of pile static load field test.

\section{Conclusion}

The stress wave theory proved to be effective in the design and construction of pile foundations of the bridge through the Kerch Strait. In the shortest time, pile-driving equipment was checked and modernized, the technology was improved, the speed of pile driving was increased, the bearing capacity of the piles was reliably determined.

With correctly conducted PDA tests, CAPWAP analysis, GRLWEAP and PLAXIS modelling in accordance with the theoretical provisions of the wave theory, the resulting bearing capacity of piles fully corresponds to the classical pile tests with a static load.

Employees of the Perm technical university has analyzed shortcomings of equipment and methods of pile testing according to the stress wave theory. At present, experimental and theoretical researches on essential modernization of devices and the software are conducted. The Russian automated and certified complex for pile testing according to the stress wave theory will be result of researches.

\section{References}

1. Results of geological survey at the site: "Construction of a transport crossing through the Kerch Strait" (2015-2016)

2. The project "Construction of a transport crossing through the Kerch Strait". (ZAO "Giprostroymost Institute, St. Petersburg, 2015-2016)

3. The program of dynamic pile tests. Object: "Construction of transport passage through the Kerch Strait” (OOO "Mostovoe bureau”, 2016)

4. https://web.archive.org/web/20170925193743/https://www.pile.com/reference-papers/

5. http://web.archive.org/web/20170925194242/https://www.plaxis.com/support/?categor $\mathrm{y}=591 /$

6. http://web.archive.org/web/20170925194444/http://www.most.life/novosti/stati/ 